\title{
Evaluation of the performance of Frying Oils using an ultrasonic technique
}

\author{
By D. Izbaim ${ }^{a^{*}}$, B. Faiz ${ }^{\mathrm{a}}$, A. Moudden ${ }^{\mathrm{b}}$, N. Taifi ${ }^{\mathrm{c}}$ and I. Aboudaoud ${ }^{\mathrm{a}}$ \\ ${ }^{a}$ Laboratory of Metrology and Information Treatment, Faculty of Sciences, \\ University Ibn Zohr, Agadir. Morocco \\ ${ }^{b}$ Superior School of Technology, University Ibn Zohr, Agadir. Morocco. \\ ${ }^{c}$ Faculty of Sciences, University Chouaib Doukkali, El Jadida, Morocco. \\ ( ${ }^{*}$ corresponding author: dizbaim @ gmail.com)
}

\section{RESUMEN}

\begin{abstract}
Evaluación de la eficacia de aceites de fritura con técnicas ultrasónicas

La eficacia de aceites de soja sin hidrogenar (USBO) y aceites de soja parcialmente hidrogenado (PHSBO) fue evaluada por comparación de sus estabilidades de fritura. La velocidad ultrasónica fue usada para evaluar los aceites. La medida de ácidos grasos libres (FFA) y compuestos polares (TPC) son típicos índices de degradación de aceites. Los aceites fueron calentados a $180^{\circ} \mathrm{C}$ en periodos de $8 \mathrm{~h}$ por día durante 4 días consecutivos. Los resultados del análisis ultrasónico muestran diferentes influencias de termooxidación en USBO y PHSBO. Las medidas ultrasónicas tuvieron una fuerte correlación con cambios químicos. Consecuentemente, el método ultrasónico es útil para obtener información en la calidad de aceites de fritura usados.
\end{abstract}

PALABRAS CLAVE: Aceite de fritura - Aceite de soja parcialmente hidrogenado - Aceite de soja sin hidrogenar Ácidos grasos - Compuestos polares - Ultrasónico.

\section{SUMMARY}

Evaluation of the performance of Frying Oils using ultrasonic technique

The performance of unhydrogenated soybean oil (USBO) and partially hydrogenated soybean oil (PHSBO) was evaluated by comparing their frying stability. Ultrasonic velocity was used to evaluate the oils. Measurements of free fatty acids (FFA) and total polar compounds (TPC) are typical indexes of oil degradation. Oils were heated at $180^{\circ} \mathrm{C}$ for periods of $8 \mathrm{~h}$ per day for 4 consecutive days. The results from the ultrasonic analyses show different influences of thermo-oxidation on USBO and PHSBO. The ultrasonic measurements had strong correlations with chemical changes. Consequently, the ultrasonic method is useful to obtain information on the quality of the used frying oils.

KEY-WORDS: Fatty acids - Frying oil - Partially hydrogenated soybean oil - Polar compounds - Ultrasonics Unhydrogenated soybean oil.

\section{INTRODUCTION}

Frying is one of oldest and simplest methods of cooking food, due to its flavor and ease of preparation. From the consumer standpoint, fried food palatability is related to unique sensory characteristics. However, the frying process involves physical, chemical and sensory changes in the food which can promote the formation of a variety of decomposition compounds with adverse nutritional implications and risks of being hazardous to human health (Marquez-Ruiz and Dobarganes, 1996). Complex changes occur during deep-fat frying which lead to thermal and oxidative decomposition. The physical changes are mainly increased viscosity, foaming and color changes and decreased smoke-point. The main chemical changes are increased free fatty acids and polar components as well as decreased levels of unsaturation, flavor quality and nutritive value (Warner, 1998). As a consequence, in many countries, the polar compound measurement is considered to be the most important test for the quality degradation of oil and a maximum level of polar compounds has been set at $25 \%$, while in some countries, a polar compound cut-off point has been established between $20 \%$ and $27 \%$ (Firestone, 1996). Some other countries also use free fatty acids. An eventual decline in food quality is a result of the increase in polar fraction (Pokorny, 1989). Weiss (1983) showed that it is mainly free fatty acids which are produced in the frying operation of which contribute to the smoke haze and therefore has a substantial effect on its smoke point. Orthoefer et al. (1996) has demonstrated that the smoke point of the frying fat affects oil absorption by the fried food.

There are many types of oils available for frying. The choice is difficult, with factors such as stability, price and nutritive value. The thermal stability of the frying oil is related to the level of hydrogenation (Arroyo et al., 1995) and the oxidative stability of the frying oil will increase with an increased degree of hydrogenation. However, these oils are undesirable from a nutrition and health standpoint (Cuesta et al., 1988). So, hydrogenated oil becomes a major concern in frying applications. Recently, partially hydrogenated oils have been increasingly adopted as an alternative to hydrogenated frying oil.

Several methods exist for controlling and assessing oil quality during deep frying. Chemical analyses provide reliable results but are time-consuming, costly, and usually require analytical expertise like 
the use of FTIR spectroscopy (Innawong et al., 2004) or chromametric methods (Xin Qing, 2003). In this respect ultrasonic techniques are fast, non-invasive and inexpensive. Many studies have been conducted to assess the composition and structure of different types of food products using ultrasound (McClements, 1997; Mulet et al., 1999). Therefore, velocity measurements can be used for oil composition and adulteration assessment (McClements and Povey, 1987; Raghupathi et al., 1980).

The objective of this study was the quantitative evaluation of quality parameters of USBO and PHSBO under thermo-oxidation using an ultrasonic technique.

\section{MATERIALS AND METHODS}

USBO and PHSBO were obtained from Cristal S.A. (Casablanca, Morocco). The oils were heated in a domestic fryer at $180{ }^{\circ} \mathrm{C}$ for $8 \mathrm{~h} /$ day over 4 days, for a total of $32 \mathrm{~h}$. Samples of $150 \mathrm{~mL}$ were periodically removed and kept at $-18^{\circ} \mathrm{C}$ for further analyses.

\subsection{Ultrasonic Measurements}

The experimental setup used for the experiments consisted of an ultrasonic transducer (5 Mhz, $0.5 \mathrm{in}$. crystal diameter, A309S-SU Model, Panametrics, Olympus), attached to a cubic container $(50 \times 50 \times 50 \mathrm{~mm})$ where the oil samples were placed. The container was introduced into a temperature-controlled bath to maintain the sample temperature and the oil was moderately stirred to prevent the formation of bubbles. The ultrasonic measurements were carried out while the oil sample was cooled from 50 to $30{ }^{\circ} \mathrm{C}$. The transducer was linked to a pulser-receiver (Sofranel Model 5073PR, Sofranel Instruments) which sent the electrical signal to a digital storage oscilloscope (LeCroy 9310M, LeCroy Cor). For the ultrasonic velocity measurement, eight signal acquisitions were taken and averaged. It can be written as:

$$
C_{\text {sample }}=2 \omega L / \varphi_{\mathrm{A} 4}-\varphi_{\mathrm{A} 2}
$$

with $\omega=2 \pi v$

To obtain the phase $\varphi$ experimentally, the FFT of signals $A 2$ and A4 were calculated (Bakkali et al., 2001).

The attenuation coefficient $(\alpha)$ was computed by fitting the experimental data to equation.

$$
\ln A=\ln A_{0}-\alpha d
$$

Where $d$ is the distance travelled by the wave, $A_{0}$ is the initial amplitude of the signal measured as the peak-to-peak voltage and $A$ is the amplitude of the signal at distance $d$. Four ultrasonic echoes were considered to compute attenuation.

\subsection{Chemical Analyses}

\section{Fatty acids}

The FA profile analysis was performed by deriving their corresponding methyl esters (Hartman and Lago, 1973) prior to the analysis by GC. Oil samples $(50 \mathrm{~mL})$ were diluted in the hexane to obtain a solution to be analyzed (about approximately $0.1 \%$ ). A VARIAN 3800 chromatograph on a CP Select CB (VARIAN) capillary column (50 m x $0.25 \mathrm{~mm}$ i.d., film thickness $0.25 \mu \mathrm{m}$ ) was used under the following temperature program: $185^{\circ} \mathrm{C}(40 \mathrm{~min}), 15^{\circ} \mathrm{C} / \mathrm{min}$ to $250^{\circ} \mathrm{C}$ (10 min). Sample injection was $1 \mu \mathrm{l}$ (split ratio $1: 100)$ at $250{ }^{\circ} \mathrm{C}$ and the flow rate of Hélium, used as carrier gas, was $1.2 \mathrm{~mL} / \mathrm{min}$. The temperature of both the split injector and flame ionization detector was $250^{\circ} \mathrm{C}$.

\section{Free fatty acids}

The FFA contents, as the percentage of oleic acid, were determined using AFNOR NF T 60204 standard method. Acid value was defined as the amount $(\mathrm{mg})$ of $\mathrm{KOH}$ required to neutralize FFA in $1 \mathrm{~g}$ of oil sample dissolved in a mixture of diethyl ether and ethanol in the presence of phenolphthalein.

\section{Polar compounds}

The contents of total polar compounds were determined following the method proposed by the IUPAC (IUPAC, 1992).

\section{RESULTS AND DISCUSSION}

\subsection{Chemical Characteristics}

Tables 1 and 2 show the results for the Fatty Acid (FA) profiles of the USBO and PHSBO carried out on the oil samples after each heating period. The FA composition of an oil has marked effects on its frying performance as well as on its physical and chemical behavior. The FA profile of the frying oils changed as a result of cyclization, polymerization and hydrolytic, oxidative and other chemical reactions promoted by frying conditions (Nawar, 1996). The linoleic acid level in deep-frying oils appears to be an obviously negative factor in

Table 1

Soybean oil FA compounds at several frying periods (\%)

\begin{tabular}{rrrrrr}
\hline & \multicolumn{1}{c}{ Oh } & \multicolumn{1}{c}{$\mathbf{8 h}$} & \multicolumn{1}{c}{$\mathbf{1 6 h}$} & \multicolumn{1}{c}{$\mathbf{2 4 h}$} & \multicolumn{1}{c}{ 32h } \\
\hline C16 : 0 & 10,75 & 11,24 & 11,50 & 11,86 & 12,29 \\
C18: 0 & 3,32 & 4,53 & 5,56 & 6,70 & 7,77 \\
C18: 1 & 22,30 & 23,02 & 29,94 & 32,62 & 35,68 \\
C18: 2 & 54,21 & 53,61 & 47,62 & 42,97 & 38,78 \\
C18: 3 & 5,88 & 5,67 & 4,80 & 3,90 & 3,49 \\
\hline
\end{tabular}


Table 2

Partially hydrogenated soybean oil FA compounds at several frying periods (\%)

\begin{tabular}{rrrrrr}
\hline & \multicolumn{1}{c}{ Oh } & \multicolumn{1}{c}{$\mathbf{8 h}$} & \multicolumn{1}{c}{$\mathbf{1 6 h}$} & \multicolumn{1}{c}{ 24h } & \multicolumn{1}{c}{ 32h } \\
\hline C16 : 0 & 13,23 & 13,35 & 13,28 & 13,24 & 13,25 \\
C18 : 0 & 7,40 & 8,29 & 9,07 & 9,46 & 9,77 \\
C18 $: 1$ & 56,10 & 57,15 & 57,91 & 59,10 & 60,08 \\
C18 : 2 & 20,60 & 19,08 & 17,75 & 16,21 & 14,98 \\
C18 : 3 & 0,56 & 0,62 & 0,47 & 0,36 & 0,32 \\
\hline
\end{tabular}

oil stability. Indeed, previous studies indicated that a lower linoleic acid content in soybean oil resulted in improved oil quality during cooking and frying (Tompkins, 2000). In this study, changes in the fatty acid profile of oils during frying are basically among the unsaturated fatty acids, whereas the saturated fatty acids are slightly increased. USBO had a higher linoleic level (54.21\%) than PHSBO $(20.60 \%)$ which means that USBO is more readily oxidized than less PHSBO. The frying stability of highly unsaturated vegetable oils such as soybean oil can be improved by hydrogenation to reduce the level of linoleic acid, and consequently to improve their oxidative and heat stabilities. However, changes in the FA profile during frying provide only limited information about these compositional changes, which are associated with oil degradation.

Free Fatty Acid (FFA) content is the frequently used test to determine the life of frying oil, but it is not recommended to be the only indicator. As a result of the cleavage of triglycerides during oxidation and hydrolysis, FFAs are formed. Previous studies of frying oils have shown that the content of FFA increases during deep-frying (Kalapathy and Proctor, 2000). FFA and other volatile substances affect the smoke point. Oils with high FFA are known to have a lower smoke point (Augustin et al., 1987), and the surfactant effect of FFA contributes to foaming which leads to further oxidation of the oil. As expected, FFA contents of the USBO and PHSBO increased significantly during frying. Initially, oils had a similar FFA content, after that, the USBO had a greater FFA level than PHSBO (Table 3).

Many researchers consider the measurement of Total Polar Components (TPC) to be the most reliable indicator of oil degradation (Fritch, 1981; Gere, 1982). Polar compounds include all oxidized and dimerized triglycerides, FFAs, monoglycerides and diglycerides, sterols, carotenoids, antioxidants, antifoamers, hydrogenation catalyst residues and soaps (Blumenthal 1996). According to Billek et al. (1978) and Paradis and Nawar (1981), polar compounds indicate the degradation of oils and the breakdown of triglycerides. Table 4 shows that TPC in USBO and PHSBO increased significantly during frying. Initially, the TPC contents of USBO and PHSBO were similar. The increase in the rate of TPC formation in the USBO was different from PHSBO. After $32 \mathrm{~h}$ of frying, the final TPC levels were $25 \%$ in USBO and $21 \%$ in PHSBO. Not to exceed the established limit (around $25 \%$ ) on frying fats and oils, the TPC-based stability is $32 \mathrm{~h}$ of frying for USBO and $42 \mathrm{~h}$ for PHSBO. This would have occurred in an even shorter time if the oil had been used for frying foods.

These parameters are indicators of the state of oil deterioration and all of them indicated that PHSBO was more stable chemically than USBO and that hydrogenation increased soybean oil stability.

\subsection{Ultrasonic Measurements}

The ultrasonic velocity and attenuation depend on the physico-chemical properties of the oil. Ultrasonic velocity decreases with the temperature in fat (McClements, 1997).

Figures $1 \mathrm{a}$ and $\mathrm{b}$ show the evolution of ultrasonic velocity with temperature for USBO and PHSBO respectively, fried for $8,16,24$ and $32 \mathrm{~h}$. As expected, as the temperature increases, the ultrasonic velocity decreases in line. After each frying period, the velocity increases with an almost constant value leading to straight parallel curves. The average velocity temperature coefficient is $-3,78 \mathrm{~m} \mathrm{~s}^{-1}{ }^{\circ} \mathrm{C}^{-1}$ and $-3,57 \mathrm{~m} \mathrm{~s}^{-1}{ }^{\circ} \mathrm{C}^{-1}$ for USBO and PHSBO respectively. Figure 2 shows the evolution of the velocity difference at $40{ }^{\circ} \mathrm{C}$ with duration of frying. Comparisons of velocity curves for each frying period of USBO and PHSBO show that velocity difference increases as duration of frying increases. Therefore, ultrasonic velocity is a parameter which allows assessing oil quality and

Table 3

Variation of $\%$ free fatty acids (as oleic acid) with different frying periods

\begin{tabular}{lccccccccc}
\hline & 0h & 4h & $\mathbf{8 h}$ & $\mathbf{1 2 h}$ & $\mathbf{1 6 h}$ & $\mathbf{2 0 h}$ & $\mathbf{2 4 h}$ & $\mathbf{2 8 h}$ & $\mathbf{3 2 h}$ \\
\hline USBO & 0,10 & 0,11 & 0,13 & 0,16 & 0,20 & 0,24 & 0,25 & 0,30 & 0,40 \\
PHSBO & 0,11 & 0,14 & 0,16 & 0,20 & 0,27 & 0,31 & 0,37 & 0,44 & 0,50 \\
\hline
\end{tabular}

Table 4

Variation of \% polar compounds with different frying periods

\begin{tabular}{lccccccccc}
\hline & $\mathbf{0 h}$ & $\mathbf{4 h}$ & $\mathbf{8 h}$ & $\mathbf{1 2 h}$ & $\mathbf{1 6 h}$ & $\mathbf{2 0 h}$ & $\mathbf{2 4 h}$ & $\mathbf{2 8 h}$ & $\mathbf{3 2 h}$ \\
\hline USBO & 3,8 & 7,7 & 12,5 & 16,6 & 18,1 & 20 & 21,9 & 23,8 & 25 \\
PHSBO & 2,5 & 6,9 & 10 & 13,1 & 15 & 16,3 & 17,8 & 18,7 & 21,2 \\
\hline
\end{tabular}



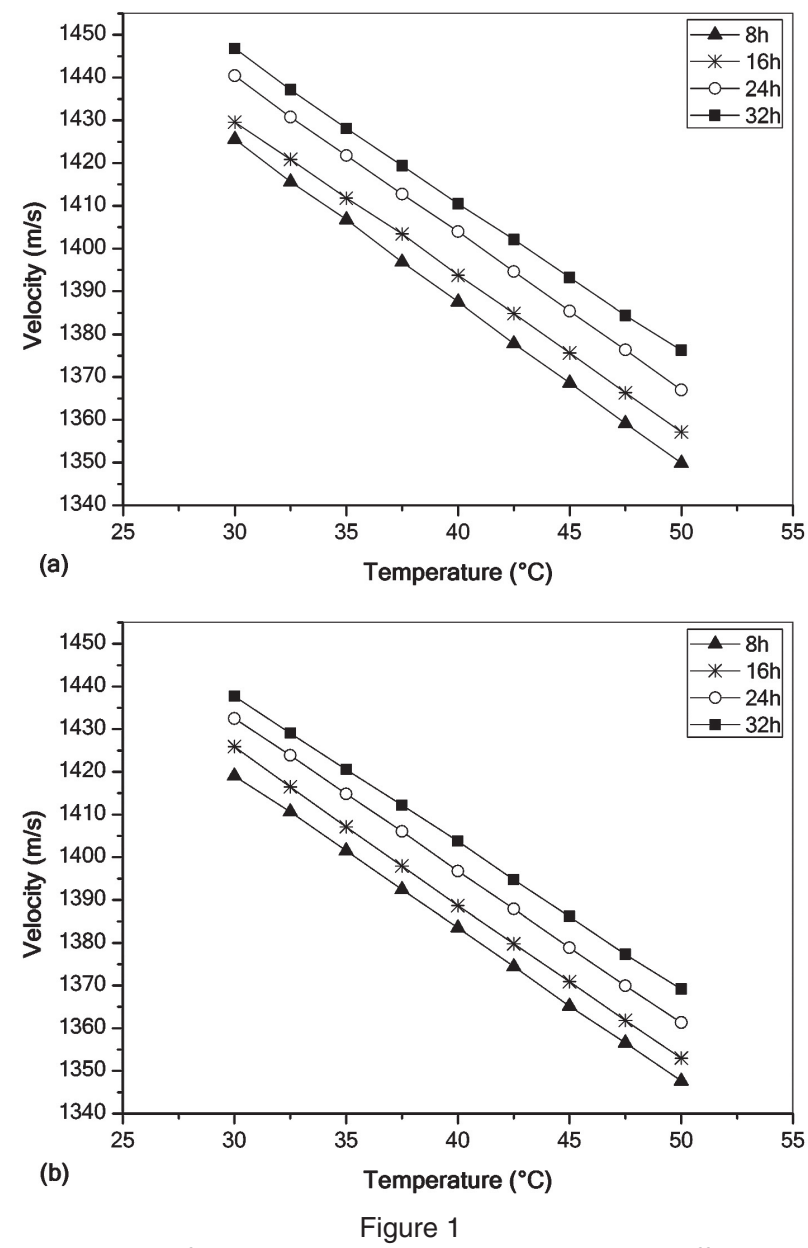

Evolution of ultrasonic velocity with temperature at different frying periods for (a) USBO and (b) PHSBO.

determining the difference between USBO and PHSBO during frying.

The ultrasonic velocity depends on time of cooling as it increases as the time of cooling increases (Figure 3). Furthermore, the velocity evolutions are very similar for both types of oils. After each frying period the velocity increases and thus it is possible to distinguish the two oils without using temperature. This shows that time of cooling seems to be an alternative to temperature.

Attenuation is also affected by temperature. As previously reported by Benedito et al. (2002), the ultrasonic attenuation decreases as temperature increases due to changes in the physico-chemical properties of the oil, although it is not so widely reported in the literature.

Relationships between the ultrasonic velocity and both TPC and FFA for USBO and PHSBO at $30^{\circ} \mathrm{C}$ are shown in Figures 4 and 5, respectively. These relationships are almost the same for both types of oils, although for the same percentage of TPC and FFA. However, significant polynomial fits were found when relating the velocity and these chemical parameters, widely considered as oil quality indicators. Therefore, the single measurement of velocity permits an estimation of the percentages of polar compounds and FFA independently of the type of oil.

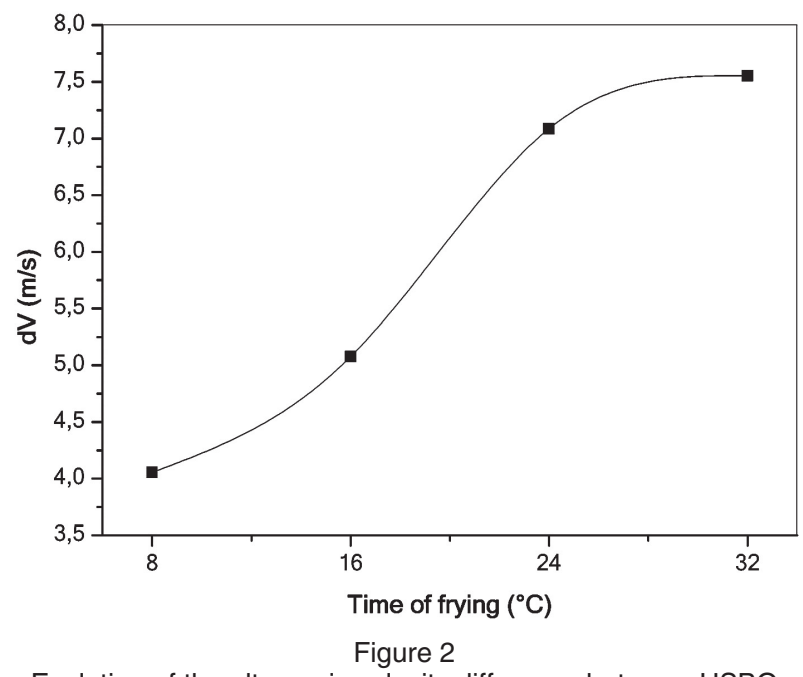

Evolution of the ultrasonic velocity difference between USBO and $\mathrm{PHSBO}$ at $40{ }^{\circ} \mathrm{C}$ for each frying period.

PHSBO performance under deep-frying conditions was significantly better than USBO with respect to ultrasonic velocity (Figure 2). In fact, majority of the studies which used ultrasonic evaluation of food properties use ultrasonic velocity, as it is more reliable than attenuation, and related to the physical and chemical properties of the medium (Benedito et al., 2007).
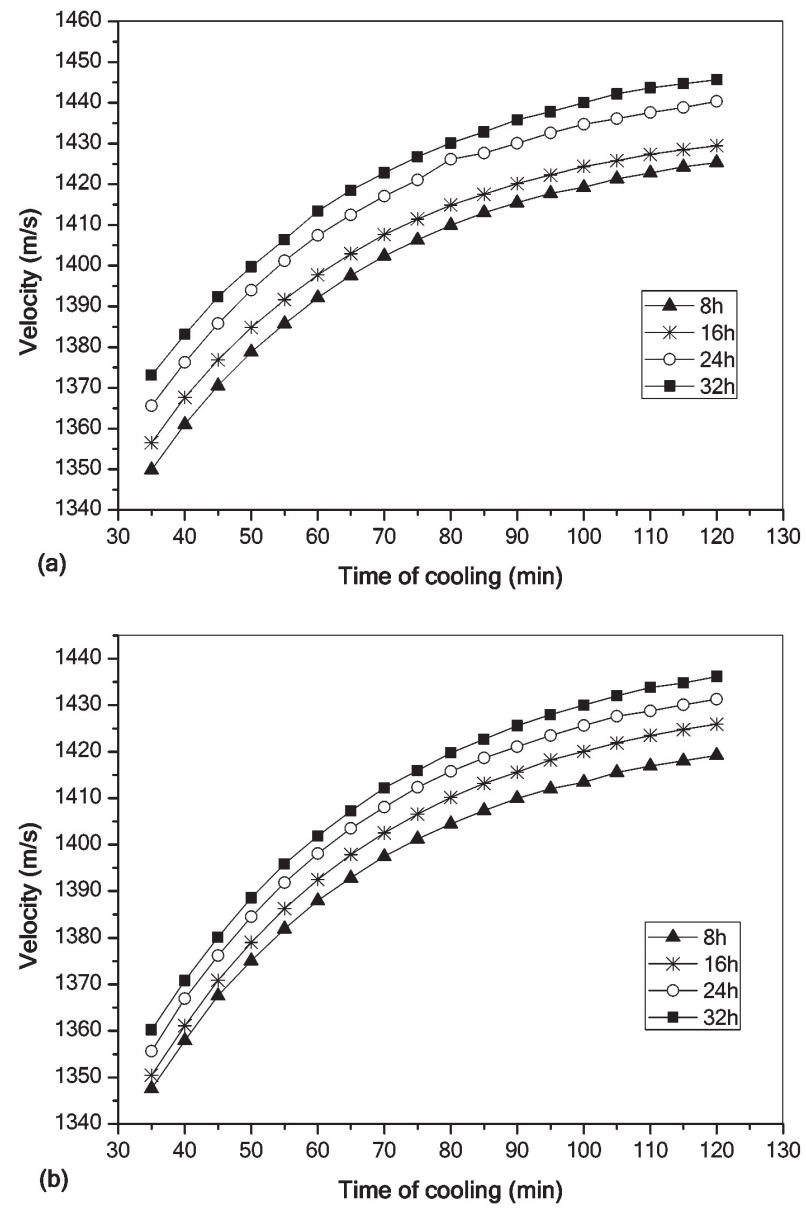

Figure 3

Variation of velocity with time of cooling for different frying periods of (a) USBO and (b) PHSBO. 


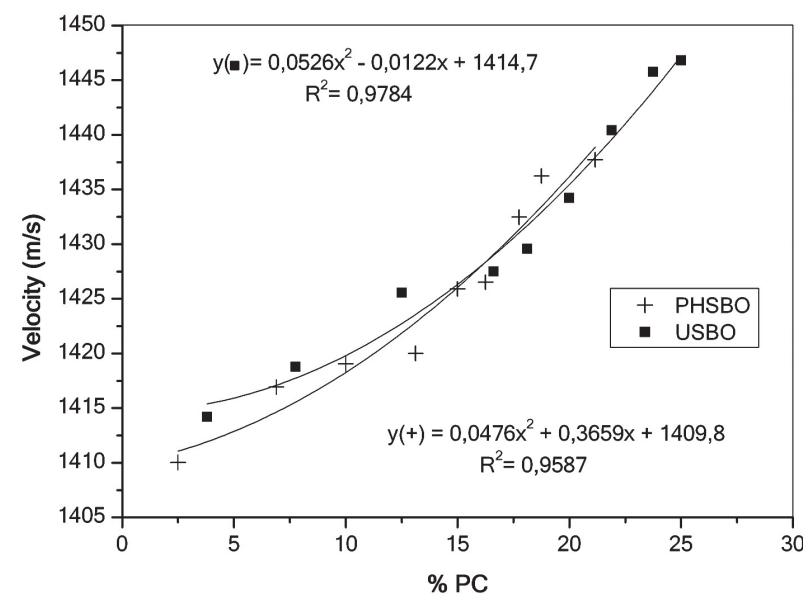

Figure 4

Relationship between ultrasonic velocity and the percentage of polar compounds for USBO and PHSBO at $30^{\circ} \mathrm{C}$.

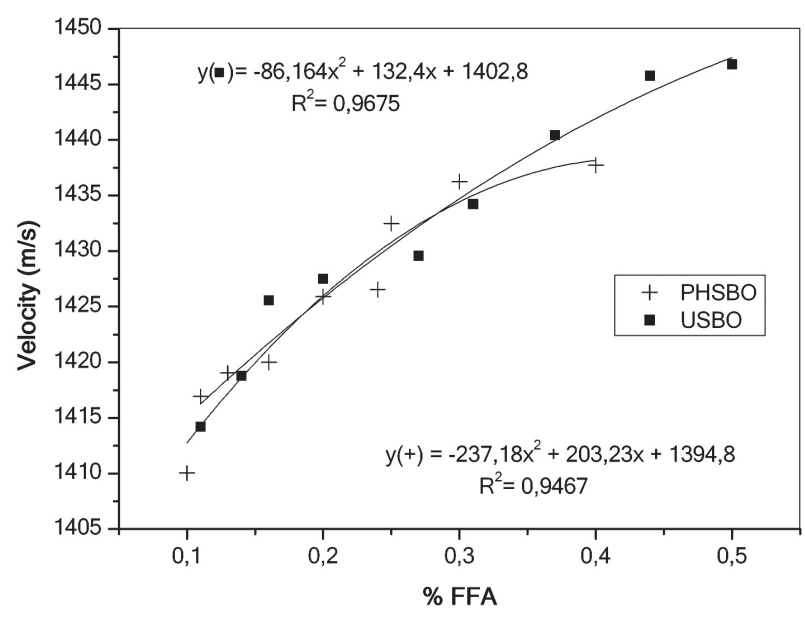

Figure 5

Relationship between ultrasonic velocity and the percentage of free fatty acids for USBO and PHSBO at $30^{\circ} \mathrm{C}$.

\section{CONCLUSIONS}

Frying duration, frying temperature and degree of hydrogenation are important factors in influencing oil lifetime and its frying properties. The ultrasonic velocity is related to the free fatty acid level and total polar compounds, showing that USBO performance was slightly lower than that of PHSBO. The ultrasonic measurement results were easily differentiated between USBO and PHSBO. Ultrasonic velocity could be used to evaluate the degradation state of oil and monitoring changes in oil during deep-frying; and ultrasonic techniques might be adapted for realtime quality control purposes of frying operations in the food industry.

\section{REFERENCES}

Arroyo R, Cuesta C, Sánchez-Montero JM, SánchezMuniz FJ. 1995. High-Performance size exclusion chromatography of palm olein used for frying. Fat Sci. Technol. 97, 292-296.
Augustin MA, Asap T, Heng LK. 1987. Relationships between measurements of fat deterioration during heating and frying in RBD olein. J. Am. Oil Chem. Soc. 64, 1670-1675.

Bakkali F, Moudden A, Faiz B, Amghar A, Maze G, Montero de Espinosa F, Akhnak M. 2001. Ultrasonic measurement of milk coagulation time. Meas Sci. Technol. 12, 2154-2159.

Benedito J, Garcia-Perez JV, Dobarganes MC, Mulet A. 2007. Rapid evaluation of frying oil degradation using ultrasonic technology. Food Res. Int. 40, 406-414.

Benedito J, Mulet A, Velasco J, Dobarganes MC. 2002. Ultrasonic assessment of oil quality during frying. $J$. Agri. Food Chem. 50, 4531-4536.

Billek C, Cuhr C, Waibel J. 1978. Quality assessments of used frying fats: A comparison of four methods. $J$. Am. Oil Chem. Soc. 55, 728-733.

Blumenthal MM. 1996. Frying technology, in Hui YH (Ed.) Bailey's industrial oil \& fat products edible oil \& fat products: Products and application technology. Wiley-Interscience, New York, 429-483.

Cuesta C, Sánchez-Muniz FJ, Varela G. 1988. Nutritive value of frying fats, in Varela $G$ (Ed.) Frying of Food: Principles, Changes, New Approaches. Ellis Horwood, Chichester, England, 112-128.

Firestone D. 1996. Regulation of Frying Fat and Oil, in Perkins EG (Ed.) Deep Frying: Chemistry, Nutrition and Practical Applications. AOCS Press, Champaign, IL, 323-334.

Fritch CW. 1981. Measurements of frying fat deterioration: A brief review. J. Am. Oil Chem. Soc. 58, 272-274.

Gere A. 1982. Studies of the changes in edible fats during heating and frying. Die Nahrung 26, 923-932.

Hartman L, Lago RCA. 1973. Rapid preparation of fatty acids methyl esters from lipids. Lab. Pract. 22, 475476.

Innawong B, Parameswarakumar M, Marcy JE. 2004. The determination of frying oil quality using a chemosensory system. Lebensm Wiss Technol 37, 35-41.

IUPAC. 1992. 1st Supplement, 7th ed, In IUPAC (Ed.), Standard methods for the analysis of oils, fats and derivatives, Pergamon Press, Oxford, England.

Kalapathy U, Proctor A. 2000. A new method for free fatty acid reduction in frying oil using silicate films produced from rice hull ash. J. Am. Oil Chem. Soc. 77, 593-598

Marquez-Ruiz G, Dobarganes MC. 1996. Nutritional and physiological effects of used frying fats. in Perkins EG (Ed.) Deep frying chemistry, nutrition and practical application. AOCS Press, Champaign, 160-182.

McClements DJ. 1997. Ultrasonic characterization of food and drinks: Principles, methods and applications. Crit. Rev. Food Sci. 37, 1-46.

McClements DJ, Povey MJW. 1987. Solid fat content determination using ultrasonic velocity measurements. Int. J. Food Sci. Tech. 59, 697-701.

Mulet A, Benedito J, Bon J, Sanjuan N. 1999. Low intensity ultrasonics in food technology. Food Sci. Technol. Int. 5, 285-297.

Nawar WW. 1996. Lipids, in Fennema OR (Ed.) Food Chemistry, Marcel Dekker, New York, 225-319.

Orthoefer FT, Gurkin S, Liu K. 1996. Dynamics of frying, in Perkins EG (Ed.) Deep Frying: Chemistry, Nutrition, and Practical Applications. AOCS Press, Champaign, Illinois, 233.

Paradis AJ, Nawar WW. 1981. A gas chromatographic method for the assessment of used frying oils: Comparison with other methods. J. Am. Oil Chem. Soc. 58, 635-638. 
Pokorny J. 1989. Flavor chemistry of deep-fat frying in oils, in SMOUSE T (Ed.) Flavor Chemistry of Foods. AOCS Press, Champaign, Illinois.

Raghupathi RC, Siva RC, Prabhu CAR. 1980. Study of adulteration in oils and fats by ultrasonic method. Curr. Sci. India 49, 185-186.

Tompkins C, Perkins EG. 2000. Frying performance of low-linolenic acid soybean oil. J. Am. Oil Chem. Soc. 77, 223-229.
Warner K. 1998. Chemistry of frying fats. in Akoh CC (Ed.) Food Lipids. Marcel Dekker, New York, USA, 167-180. Weiss TJ. 1983. Food oils and their uses, The AVI Publishing Co, Westport, 16.

Xin Qing X. 2003. A chromametric method for the rapid assessment of deep frying oil quality. J. Sci. Food Agr. 83, 1293-1296.

Recibido: $18 / 8 / 09$ Aceptado: 2/10/09 